\title{
1. Introduction: ageing in place in the Western Asia-Pacific
}

\author{
Bruce Judd, Edgar Liu and Kenichi Tanoue
}

\section{INTRODUCTION}

Population ageing is an international phenomenon (United Nations Department of Economic and Social Affairs [UN], 2017) with profound social and economic implications (Harper, 2014; Rouzet et al., 2019; World Health Organization [WHO], 2015) and the nature of the built environment at various scales is critical to optimizing the social participation and well-being of older people, who increasingly comprise larger shares of the population. It is, however, occurring at different rates in different countries, eliciting policy responses reflecting local cultural, political and economic settings (UN, 2017). A common response of governments is to move toward policies that encourage ageing in place in one's own home and community for as long as possible in order to reserve more costly institutional care for those with higher needs such as frailty and dementia (Philips, Ajrough and Hillcoat-Nallétamby, 2010). It is often seen as a win-win policy, favoured by governments because of the potential cost savings to counter increasing dependency ratios as well as by the majority of older people themselves who prefer to remain independent and engaged with their communities in their later years. It is also argued that remaining in one's own home and maintaining active involvement in a familiar community can contribute to positive health and well-being in older age (WHO, 2015). However, successful ageing in place is only possible with access to appropriate care services and a supportive built environment.

The focus of this book is on ageing-in-place policies and practice in the Western Asia-Pacific, particularly in relation to policies and practice regarding the built environment. This corresponds with the Western Pacific Region as defined by the World Health Organization (WHO, 2020a), which extends from Japan in the north to New Zealand in the south and from China in the west to the many small island nations in the western Pacific Ocean. Our particular focus is on Japan and China (including Hong Kong and Taiwan) in the northern hemisphere, and Australia and New Zealand in the southern hemisphere, both of which have increasingly been seen as part of Asia given their geographic location in the Western Pacific Region, the importance of trade relationships with East Asian countries, and increasing Asian immigration.

There are a number of reasons for this focus on ageing in place in the Western Asia-Pacific. First, Asia includes the country with the most advanced ageing internationally (Japan), and another (China) with the highest total population that is on a very steep ageing trajectory, both requiring sustained policy responses in the face of a breakdown in family support and care traditions (Chang, 2014; Miyanaga, 1993; Rein, 2014). Second, the bulk of the existing 
literature on ageing in place and the built environment is Eurocentric, and much of the East Asian literature has not been published in English. Third is the very different cultural contexts and social change in East Asia regarding ageing, the family and society in contrast with the more Anglo-European cultural and socio-political origins of Australia and New Zealand, from which contrasting mutual learnings are possible that can inform and improve responses in other contexts within and outside of the region.

In this introductory chapter, it is important to examine the concepts of 'ageing' and 'place' from the literature, along with their combined meaning as 'ageing in place' and the role of the built environment in this process. This is done from the perspective of environmental gerontology, which recognizes the role of the physical environment in the ageing process along with the important health and socio-cultural aspects of ageing.

\section{AGEING}

Ageing is an inevitable biological process for individual human beings, resulting in a reduction of physical and mental abilities over time, leading eventually to death. However, it is important to recognize the great diversity of ability levels at any particular age (WHO, 2015). Who might be considered 'older' is, therefore, not merely chronological and hence difficult to define as it is situation and context dependent.

The World Health Organization (WHO) defines an older person as 'a person whose age has passed the median life expectancy at birth' (WHO, 2015, p. 230). However, for practical purposes, the common age thresholds used in the developed world for statistical purposes often relate to retirement and pension eligibility ages, most commonly 60 or 65 years of age, some with slightly lower ages for women, or as low as 45 or 50 for some disadvantaged communities and developing countries with lower life expectancy (Koward and Dowd, 2001). The United Nations (2019a) uses 65 as the threshold age for its international comparative statistics, as do the official statistics of the Western Asia-Pacific countries that are the focus of this book.

However, ageing is not only an individual phenomenon, it is also a societal one. With improvements in sanitation and health due to medical advances, death rates have been reducing internationally and fertility decreasing due to increasing education and workforce participation of women. The combination of these two primary factors has led to the phenomenon of population ageing, an international trend, most advanced in developed economies such as Japan and certain European countries (Italy, Spain and Germany) but most rapid in developing countries, though starting from a much lower base (UN, 2019b). Figure 1.1 shows the extent of population ageing in the countries and regions that are the focus of this book - Japan, China (the People's Republic of China), Hong Kong Special Administrative Region [SAR], Taiwan, Australia and New Zealand.

Japan is an important inclusion in this book, not only as the most advanced ageing society of these six cases, but also as the most highly aged country internationally, with an estimated 28.4 percent of its population aged 65 or over in 2020, expected to increase to 38.2 percent by 2050 and 42.3 percent by 2100 (UN, 2019a). Contributing factors to Japan's 'super-aged' society have been rapidly declining fertility, increasing longevity and low immigration in the post-war period. This has led to Japan's declining population from a peak of 128 million in 2008 (e-Stat, 2017) predicted to reduce by 25 percent by 2050 (Muramatsu and Akiyama, 2011). Such depopulation has been influential in Japan's shrinking regional communities and 


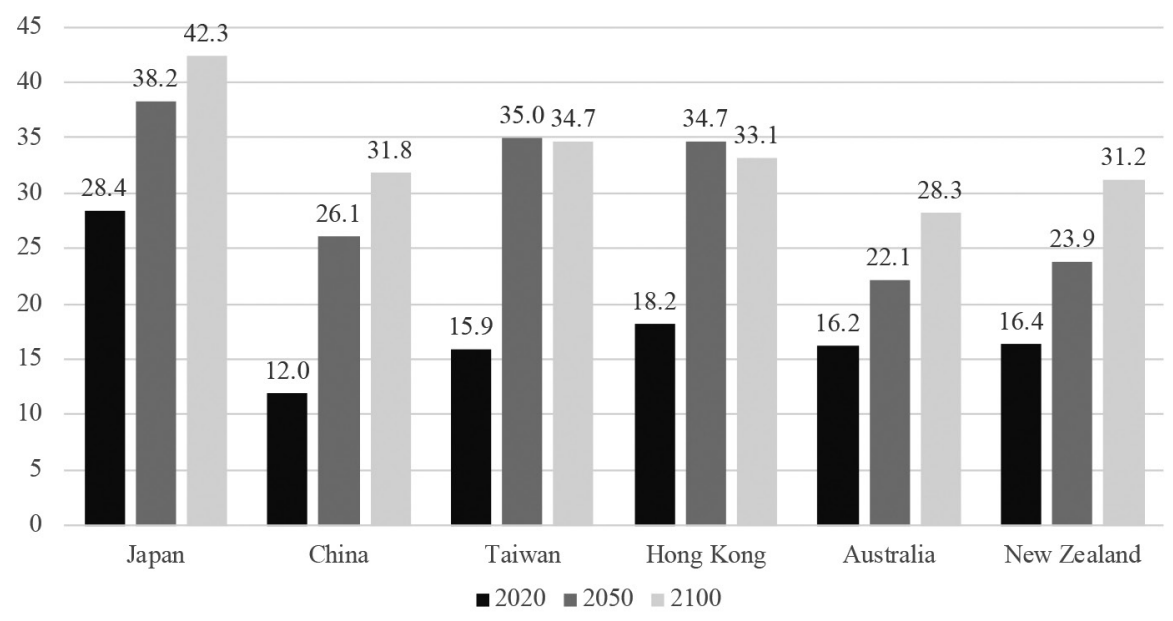

Source: UN (2019a).

Figure 1.1 Percentage of people aged 65+ in selected Western Asia-Pacific countries, 2020, 2050 and 2100, median projections

cities and contributed to increasing housing vacancies and economic stagnation since the early 1990s (Kubo and Mashita, 2020; Wakabayashi, 2020).

In contrast, the level of population ageing in the People's Republic of China (PRC) in 2020 is the lowest of these six societies, estimated at only 12.0 percent aged 65 or older in 2020 , yet on a much steeper trajectory - it is expected to reach 26.1 percent by 2050 and 31.8 percent by the end of the century, just 10.1 percentage points behind that estimated for Japan in the same year. A contributing factor has been its decades-long but recently abolished One Child Policy (resulting in very low fertility, at below replacement level) and increasing life expectancy. Since it is the most populous country in the world, the numbers of people estimated to be aged 65 and over in 2020 is a staggering 172 million and is projected to almost double to around 365 million in just 30 years by 2050. While Taiwan and the Hong Kong SAR have higher current levels of ageing (15.9 percent and 18.2 percent, respectively, in 2020) than the PRC, they are also on similarly high trajectories toward a projected 35.0 percent and 34.7 percent, respectively, by mid-century, a little higher than that expected for the PRC but likely to stabilize at around those levels by the end of the century, while Japan and PRC continue to age.

Australia and New Zealand are quite similar in their ageing profile and trajectory, with the older $(65+)$ population estimates representing 16.2 percent and 16.4 percent, respectively, in 2020. Their growth is more modest than the northern hemisphere cases represented in this book, rising to 22.1 percent and 23.9 percent, respectively, by mid-century, thereby also reaching the status of being 'super-aged' societies. By the end of the century, however, they are projected to reach 28.3 percent and 31.2 percent, respectively, only a few percentage points lower than predicted for the PRC, Hong Kong SAR and Taiwan, but still well short of that projected for Japan. 
However, population ageing must also be viewed within the different socio-cultural, political and built environment contexts of the individual countries and regions that are the focus of this book. In the Asian cases, there has been a tradition of filial piety where children have been obligated to cohabit with and care for elderly parents, which is breaking down with urbanization of education and employment, and in the case of PRC the legacy of the One Child Policy (Deutsch, 2006). Japan has been facing the consequences of population ageing for some time (Muramatsu and Akiyama, 2011) and by necessity has developed its own policy responses, including attempts to improve housing and urban environments through age-friendly technologies, domestic fixtures and more age-appropriate housing design. Yet, unlike its Asian neighbours, it faces the challenges of depopulation, most pronounced in rural areas, and the breakdown of family care traditions, and high exposure to natural disasters to which older people are amongst the most vulnerable (Evans, 2009; Tanida, 1996). China is grappling with issues of ensuring appropriate housing and communities in a cultural environment where family care traditions are also breaking down due to increasing internal and international migration, rapid urbanization and increases in residential density. However, its socio-political traditions of filial piety and collectivism remain influential on notions of ageing in place that differ significantly from Western models based more on individualism and choice ( $\mathrm{Yu}$ and Rosenberg, 2017). In the Anglo-Celtic cultural traditions of Australia and New Zealand, the generations have lived more independently with provision of institutional care for the elderly; however, multigenerational living is increasing for financial, mutual support needs and immigration of those from cultures with filial piety traditions (Liu and Easthope, 2016; Van der Pas, 2009).

Political systems also vary considerably among the cases, with different powers of the state, ageing and built environment policy frameworks, jurisdictional responsibilities, planning controls and regulatory systems, all of which influence housing and urban outcomes for older people. Nevertheless, despite these socio-cultural and political differences, and the diversity of population ageing trajectories, the countries and regions represented in this book also face some common policy and built environment challenges in addressing the needs of their older citizens.

While Hong Kong and Taiwan have similar cultural traditions to the PRC, they differ considerably in their political systems. While part of China, due to its origins as a British Colony, Hong Kong is administered differently under the 'one country, two systems' approach that was agreed at its handover to China in 1997. Its policy approaches, therefore, continue to be influenced by both its British colonial past as well as those of the PRC. While Taiwan's cultural heritage of Confucianism and filial piety is also a common one with PRC and Hong Kong, its political system has undergone considerable change since 1945, evolving into a democratic government modelled more on Western democracies.

While Australia and New Zealand are similar in many ways due to their Anglo-European cultural and political influences and policy models, and recent neoliberal shifts away from the welfare state, the two countries do differ in some important jurisdictional arrangements and policy settings. Australia is a federation of six states and two territories with responsibilities divided between national, state/territory and local governments around funding and delivery of health, ageing and housing services. While highly urbanized, in contrast to the northern hemisphere cases the settlement form is largely low-density, single-family, suburban housing in which the majority of older people live independently (Judd et al., 2014). It also has 
a small, regulated age-specific retirement village sector and a growing manufactured housing estate (also known as lifestyle villages) industry. Key population ageing and housing issues in Australia are its growing emphasis on ageing in place, yet much of the housing stock is inappropriate, with poor access to services in many of the suburban areas (Judd et al. 2010), and the lack of adequate funding for home modifications and community-based care services.

New Zealand has only two levels of government - national and local - and a much smaller population. Key housing issues for older people are its dispersed low-density suburban settlement forms, reducing rates of homeownership, lack of suitable housing options for ageing in place, housing affordability, health issues arising from poor housing quality, earthquake vulnerability, and the cultural needs of its Māori and Pacific Islander populations (Koopman-Boyden and Waldegrave, 2015; Saville-Smith et al., 2016). New Zealand introduced a Healthy Ageing Strategy in 2016, which acknowledges the critical importance of housing and transport for people to age well in their own communities (NZ Ministry of Health, 2016). Its Ageing Well National Science Challenge programme has also funded major research projects into ageing in place, downsizing and community resilience through the Centre for Research, Evaluation and Social Assessment (CRESA, 2020). Recent legislation for minimum standards for heating, insulation, ventilation, draught prevention and moisture penetration in rental accommodation has also been introduced (NZ HUD, 2020), particularly relevant to vulnerable older renters.

\section{AGEING AND PLACE}

The notion of 'place' is an elusive and contested concept. Although located in physical space, what constitutes place cannot be defined by physical dimensions and features alone. As Cresswell (2015, pp. 15-16) observes, 'place is a more abstract concept than space' and 'when humans invest meaning in a portion of space and then become attached to it in some way (naming is one such way) it becomes a place'. Places are locales of meaning, identity and belonging for individuals or shared by groups. They can vary in scale from intimate, highly personal places such as private rooms in a home or work environment, to shared places such as the home and its land, to a local neighbourhood, a village, town or suburb, or a wider city or region, and even the country to which people have a sense of attachment and belonging (Freestone and Liu, 2016). Places are not static but change over time in response to changing personal or socio-cultural needs and values. They can have positive or negative associations depending on people's experiences with them and can be socially or culturally inclusive or exclusive and, therefore, have implications for social justice and equity. As such, they can also have political significance as locales of social change. Importantly for the theme of this book, places also have an important role in the physical and psychological health and well-being of people, particularly for those of older age.

The relationship between ageing and place is a central focus of the field of environmental gerontology that has emerged over the last 45 years, drawing on gestalt psychologist Kurt Lewin's field theory and his equation $B=f(P . E)$ (that is, Behaviour is a function of the Person and their Environment), the urban ecology approach of the Chicago School of Sociology in the 1920s and 1930s, and environmental psychology in the 1960s and 1970s (Rowles and Bernard, 2013). According to Wahl and Weisman (2003, pp. 616-17), environmental gerontology is 'focused on the description, explanation, and modification or optimization of the relation between elderly persons and their sociospatial surroundings', including 'the varieties 
of private housing arrangements of older people in terms of household composition, ownership, housing standards, time of residency, and residential satisfaction' as well as 'the nature and impact of home modifications, including both theoretical models and planning guidelines for the refitting of homes, and with the scope of institutional ageing from relocation to the design of dementia units and other care settings,. . .studying the role of neighbourhoods as they present both opportunities and constraints to their residents, and with community settings as the locus of ageing within a broader, social policy perspective'. It is, therefore, by nature, a multidisciplinary field involving contributions from the social sciences (anthropology, sociology, psychology, human geography, political science and economics), health sciences (geriatrics, public health, physiotherapy and occupational therapy) and the built environment disciplines (architecture, landscape architecture and urban planning).

Foundational to the development of environmental gerontology were Lawton's theories on the ecology of ageing and 'environmental press' that explain the dynamic relationship between an older person's competence and environmental variables or 'press' (Lawton and Nahemow, 1973). This became reconceptualized as person-environment fit (P-E fit), which has been an influential construct in research and practice for understanding the fit (or misfit) between older people's needs and their home and neighbourhood environments (Iwarsson, 2004; Kahana et al., 2003; Oswald et al., 2005), and adoption of home modifications and adaptable and universal design to better accommodate changing levels of competence with age (Hwang et al., 2011; Sanford, 2012; Webb, Williams and Smith, 2011). There has also been a growing focus in environmental gerontology on the experiential aspects of ageing and place, including the meaning, significance and attachment to the home (Rowles, 1978; Rowles and Chaudhury, 2005; Rubenstein, 1990; Wiles et al., 2009), local neighbourhood (Peace, Holland and Kellaher, 2006; Rowles, 1993; Smith, 2009; Wiles et al., 2012), and the experience of relocating and reconstructing a sense of place (Löfqvist et al., 2013; Wu et al., 2015).

The creation of home as a place of identity and belonging accumulates over time and hence increases in significance and meaning as people age. As Rowles and Bernard (2013, p. 10) explain, 'habitation of an environment over an extended period generates temporal depth in the experience of place through repetition of patterns of use, increasingly differentiated awareness, and the accumulation of layers of emotional attachments'. Further, 'over time, place gradually comes to embody the self as it provides a reservoir of experiences grounded in our life experience that we can resurrect and vicariously relive and reconfigure as we develop, refine, and reinforce our identity. As layer upon layer of meaning in place is accumulated, the outcome is a sense of being in place' (ibid.). Similarly, people develop a sense of identity and emotional attachment to the local neighbourhood over time through their social connections with other residents, familiar retail, health and transport services, and recreational amenities (Peace et al., 2006; Smith, 2009; Wiles et al., 2012). Loss of such attachment to home and neighbourhood through involuntary relocation can be a stressful or even traumatic experience of disconnection and building attachment to their new home and neighbourhood may not be an easy process (Rowles and Bernard, 2013). This helps to explain why internationally most older people prefer to 'stay put' and age in place (Lansperry and Hyde, 1997).

From an international policy perspective, the WHO has also focussed on issues of ageing and place through its Age-friendly Cities and Communities programme (AFCC). Conceived at the 28th International Association of Gerontology and Geriatrics World Congress in Brazil in 2005, and led by epidemiologist Alexandre Kalache, WHO published its Global Age-friendly 
Cities: A Guide in 2007. Eight key elements of an age-friendly city were identified, three of which focus on the built environment (outdoor spaces and buildings, transportation, and housing) and five on the social environment (social participation, respect and social inclusion, civic participation and employment, communication and information, and community support and health services). Guidelines and a checklist were provided for each of these elements. These were later amended to align better with WHO's Global Strategy and Action Plan on Ageing and Health (WHO, 2017) and Decade of Action on Healthy Ageing (2020-2030) plan (WHO, 2020b), and the UN's New Urban Agenda (Habitat III, 2017) and the Sustainable Development Goals (UN, 2019c), emphasizing a cycle of continuous improvement involving a fourfold process of engagement and understanding, planning, acting and measuring progress on age-friendly goals.

In 2010, the AFCC established the Global Network for Age-Friendly Cities and Communities, which reached a membership of 1000 local and city government members over the following ten years. Amongst the countries and regions in this book, this includes three member jurisdictions in Japan, two in China, two in New Zealand (also an affiliate member nationally), and, in Australia, the state of Western Australia and 25 cities and municipalities throughout the country including the national capital Canberra. Over the next decade, the network should provide an important database of member states' strategies and performance against age-friendly city and community guidelines, including those related to housing and urban environments.

\section{AGEING IN PLACE}

The term 'ageing in place' brings together the two important but complex elements - ageing (both individual and population) and place (both the home and neighbourhood). A widely held definition of ageing in place is that of the US Centers for Disease Control and Prevention (CDC, 2009), which was also adopted by the WHO (2015, p. 36): 'The ability of older people to live in their own home and community safely, independently, and comfortably, regardless of age, income or level of intrinsic capacity'. The term was later expanded by the WHO (2015, p. 225) to 'ageing in the right place', which 'extends this concept to the ability to live in the place with the closest fit with the person's needs and preferences - which may or may not be one's own home'. This includes the possibility of moving from one's established residence to another that better matches their present and future needs but is generally understood to not include moving to age-segregated housing.

It is well established internationally that the familiar, often long-standing, family home and neighbourhood are the 'place' in which most older people desire to continue to live for as long as possible (American Association of Retired Persons [AARP], 2000, 2010; Olsberg and Winters, 2005; Pynoos, Caraviello and Cicero, 2009). Drawing on the environmental gerontology literature, Fogel (1993, p. 19) identified six benefits of the home for older people: '(1) independence, such as privacy and control over physical features of the home environment'; '(2) familiarity of a particular home environment, for example, ease of finding one's way around'; '(3) residence in a specific neighbourhood, including a social network of friends and neighbours, and access to community services'; '(4) activities of home maintenance, as a source of physical and mental exercise and as a source of meaning', '(5) the home as a place 
to entertain friends and family, to reciprocate hospitality and to pursue avocational activities'; and '(6) the home as a locus of meaning - the site of important and memorable life events'.

Ageing in place is favoured by governments dealing with ageing populations who - observing increasing old age dependency ratios, the escalating costs of aged care to the economy, and cognisant of older people's preferences - see it as a means of containing public expenditure (Australian Treasury, 2010). Policy settings to promote ageing in place in various countries vary considerably but can include increasing the level of care services delivered to the home; financial support for home modifications; and guidelines, incentives or regulations for accessible, adaptable or universal design of housing and enabling technologies. At the neighbourhood level, they can include improving the accessibility and safety of public pathways and street crossings, open spaces, seating, shelter, toilets, lighting at night and convenient walkable access to retail, community facilities and accessible public transport (Burton and Mitchell, 2006; Judd et al., 2010; WHO, 2007).

However, despite the strong preference of the majority of older people to remain at home for as long as possible, ageing in place is no panacea for all older people and some would prefer to move because of dislike of their home or community (Hillcoat-Nallétamby and Ogg, 2014). Ageing in place is often not possible given the characteristics of conventional housing types in many countries, such as two-storey dwellings and stair-only access apartment blocks, still common in many of the societies represented in this book, resulting in a disjunction between government policy ideals and the reality for older people living in inappropriate housing or neighbourhood environments. Ageing in place can also place the burden of care onto a similarly older partner or other family member or result in loneliness and isolation for some, with limited mobility and access to family and community. It can be unsafe if located in a troubled neighbourhood, or uncomfortable and unhealthy for vulnerable older people on low incomes living in rental housing of poor quality that is difficult to heat or cool (Howdon-Chapman et al., 2012).

Where existing housing types are not suitable, or easily modifiable, for ageing in place, age-friendly alternative housing options are essential. However, these are often not available in the housing market, or appropriately located, and the housing industry and governments have often been slow in increasing age-friendly, accessible and affordable housing options close to retail, transport and other services (Judd et al., 2014; Saville-Smith et al., 2016). Nevertheless, ageing in place is likely to remain favoured by most older people and high on the agenda of governments in addressing the impacts of an ageing population.

\section{STRUCTURE OF THE BOOK}

Following this introductory chapter, the book is structured thematically in three parts, each reflecting contemporary research into ageing in place concerning design, planning and policy from across the Western Asia-Pacific region. Its focus is deliberately broad, considering aspects of ageing and the built environment from room to region in the six societies represented, and the policies that enable or inhibit ageing in place. Its contributors are likewise diverse in disciplinary perspectives, including contributions from architecture, urban planning, sociology, human geography, environmental anthropology and ergonomics. The countries and regions of focus in this book provide an opportunity to understand the similarities and con- 
trasts in how ageing in place is understood and operationalized in policy and practice in these diverse, yet strongly connected socio-political societies in the Western Asia-Pacific.

The five chapters in Part I: Design, highlight considerations and current shortcomings in the design of housing (Judd, Kose, Zhang and Lei, and Muraki) and support facilities (Hwang) for older people ageing in place. In Part II: Planning, the focus shifts to a broader scale, reflecting on ageing in place at the neighbourhood (Bridge and Li et al.), metropolitan (Atkins) and regional scales (Tani et al.), including in response to natural disasters affecting a region (Tanoue). Part III: Policy, comprises a mix of philosophical discussions of important housing concepts relevant to ageing in place (Sukenari and Saville-Smith), as well as reflections on how different policies and initiatives facilitate it (Chui) and influence decisions regarding the family and care-giving (Liu). The book ends with a brief conclusion (Liu and Judd), drawing together key concepts and findings of the authors and their implications for future research, policy and practice in the endeavour to improve the built environment for an ageing population.

\section{NOTE}

1. A country is considered an 'ageing society' if over 7 percent of its population is aged 65 or over, an 'aged society' if over 14 percent, and 'super-aged' if over 21 percent (Kudo, Mutisya and Nagao, 2015; Lee, Mason and Park, 2011).

\section{REFERENCES}

American Association of Retired Persons [AARP] (2000), Fixing to Stay: A National Survey on Housing and Home Modification Issues, Washington, DC: AARP.

American Association of Retired Persons [AARP] (2010), Home and Community Preferences of the 45+ Population, Washington, DC: AARP.

Australian Treasury (2010), Australia to 2050: Future Challenges (Intergenerational Report 2010), Canberra: Commonwealth of Australia.

Burton, E. and L. Mitchell (2006), Inclusive Urban Design: Streets for Life, Amsterdam: Elsevier.

Centers for Disease Control and Prevention [CDC] (2009), 'Healthy places terminology: aging in place', accessed 30 January 2020 at https:/www.cdc.gov/healthyplaces/terminology.htm.

Centre for Research Evaluation and Social Assessment [CRESA] (2020), 'Projects and publications', Wellington: CRESA, accessed 25 April 2020 at https://cresa.co.nz/projects-and-publications/.

Chang, K.-C. (2014), 'Individualization without individualism: compressed modernity and obfuscated family crisis in East Asia', in E. Ochiai and L. Hosoya (eds), Transformation of the Intimate and the Public in Asian Modernity, Leiden: Brill, pp. 37-62.

Cresswell, T. (2015), Place: An Introduction, 2nd edition, Chichester: Wiley Blackwell.

Deutsch, F. (2006), 'Filial piety, patrilineality, and China's one-child policy', Journal of Family Issues, 27(3), 366-89.

e-Stat (2017), 'Statistics of Japan: population by sex (as of October 1 of Each Year) - total population, Japanese population (from 2000 to 2015)', Tokyo: Statistics Bureau of Japan, accessed 13 April 2020 at https://www.e-stat.go.jp/en/stat-search/files?

Evans, J. (2009), 'Mapping the vulnerability of older persons to disasters', International Journal of Older People Nursing, 5, 63-70.

Fogel, B. (1993), 'Psychological aspects of staying at home', in J. Callaghan (ed.), Aging in Place, Amityville, NY: Baywood, pp. 19-28.

Freestone, R. and E. Liu (eds) (2016), Place and Placelessness Revisited, New York: Routledge.

Habitat III (2017), New Urban Agenda, New York: United Nations.

Harper, S. (2014), 'Economic and social implications of aging societies', Science, 346(6209), 587-91. 
Hillcoat-Nallétamby, S. and J. Ogg (2014), 'Moving beyond "ageing in place": older people's dislikes about their home and neighbourhood environments as a motive for wishing to move', Ageing and Society, 34, 1771-96.

Howdon-Chapman, P., H. Viggers and R. Chapman et al. (2012), 'Tackling cold housing and fuel poverty in New Zealand: a review of policies, research and health impacts', Energy Policy, 49, 134-42.

Hwang, E., A. Cummings, A. Sixsmith and J. Sixsmith (2011), 'Impacts of home modifications on aging-in-place', Journal of Housing for the Elderly, 25(3), 246-57.

Iwarsson, S. (2004), 'Assessing the fit between older people and their physical home environments: an occupational therapy research approach', Annual Review of Gerontology and Geriatrics, 23, 85-109.

Judd, B., E. Liu and H. Easthope et al. (2014), Downsizing Amongst Older Australians: AHURI Final Report No. 214, Melbourne: Australian Housing and Urban Research Institute [AHURI].

Judd, B., D. Olsberg and J. Quinn et al. (2010), Dwelling, Land and Neighbourhood Use By Older Home Owners: AHURI Final Report No. 144, Melbourne: Australian Housing and Urban Research Institute [AHURI].

Kahana, E., M. Lovegreen, B. Kahana and M. Kahana (2003), 'Person, environment, and personenvironment fit as influences on residential satisfaction of elders', Environment and Behaviour, 35(3), 434-53.

Koopman-Boyden, P. and C. Waldegrave (2015), 'Introduction', in P. Koopman-Boyden and C. Waldegrave (eds), Enhancing Well-Being in an Ageing Society: 65-84 Year Old New Zealanders in 2007, Hamilton: The Population Studies Centre, University of Waikato/Wellington: Family Centre Social Policy Research Unit, pp. 1-7.

Koward, P. and J. Dowd (2001), 'Proposed working definition of an older person in Africa for the MDS Project', Geneva: World Health Organization.

Kubo, T. and M. Mashita (2020), 'Why the rise in urban housing vacancies occurred and matters in Japan', in T. Kubo and Y. Yui (eds), The Rise in Vacant Housing in Post-Growth Japan: Housing Market, Urban Policy, and Revitalizing Aging Cities, Singapore: Springer Nature, pp. 3-22.

Kudo, S., E. Mutisya and M. Nagao (2015), 'Population aging: an emerging research agenda for sustainable development', Social Sciences, 4, 940-66.

Lansperry, S. and J. Hyde (eds) (1997), Staying Put: Adapting the Places Instead of the People, New York: Routledge.

Lawton, M. and L. Nahemow (1973), 'Ecology and the aging process', in C. Eisdorfer and M. Lawton (eds), The Psychology of Aging and Adult Development, Washington, DC: American Psychological Association, pp. 619-74.

Lee, S.-E., A. Mason and D. Park (2011), 'Why does population aging matter so much for Asia? Population aging, economic security and economic growth in Asia', ADB Economics Working Paper Series, No. 284. Manila: Asian Development Bank.

Liu, E. and H. Easthope (2016) 'Living with the family in Australian cities', in E. Liu and H. Easthope (eds), Multigenerational Family Living: Evidence and Policy Implications from Australia, London: Routledge, pp. 1-13.

Löfqvist, C., M. Granbom and I. Himmelsbach et al. (2013), 'Voices on relocation and aging in place in very old age - a complex and ambivalent matter', The Gerontologist, 53(6), 919-27.

Miyanaga, K. (1993), The Creative Edge: Emerging Individualism in Japan, New Brunswick, NJ: Transaction Publishers.

Muramatsu, N. and H. Akiyama (2011), 'Japan: super-aging society preparing for the future', The Gerontologist, 51(4), 425-32.

NZ HUD (2020), 'About the healthy home standards', Wellington: Ministry of Housing and Urban Development, accessed 24 April 2020 at https://www.hud.govt.nz/residential-housing/healthy-rental -homes/healthy-homes-standards/about-the-healthy-home-standards/.

NZ Ministry of Health (2016), Healthy Ageing Strategy, Wellington: Ministry of Health.

Olsberg, D. and M. Winters (2005), Ageing in Place: Intergenerational and Intrafamilial Housing Transfers and Shifts in Later Life: AHURI Final Report No. 88, Melbourne: Australian Housing and Urban Research Institute [AHURI].

Oswald, F., A. Hieber, H.-W. Wahl and H. Mollenkopf (2005), 'Ageing and person-environment fit in different urban neighbourhoods', European Journal of Ageing, 2, 88-97. 
Peace, S., C. Holland and L. Kellaher (2006), Growing Older: Environment and Identity in Later Life, Maidenhead: Open University Press.

Philips, J., K. Ajrough and S. Hillcoat-Nallétamby (2010), Key Concepts in Social Gerontology, London: SAGE

Pynoos, J., R. Caraviello and C. Cicero (2009), 'Lifelong housing: the anchor in aging-friendly communities', Generations, 33(2), 26-32.

Rein, S. (2014), The End of Copycat China: The Rise of Creativity, Innovation, and Individualism in Asia, Hoboken, NJ: John Wiley \& Sons.

Rouzet, D., A. Sanchez, T. Renault and O. Roehn (2019), 'Fiscal challenges and inclusive growth in ageing societies', OECD Economic Policy Papers, No. 27, Paris: OECD Publishing.

Rowles, G. (1978), Prisoners of Space? Exploring the Geographical Experience of Older People, Boulder, CO: Westview Press.

Rowles, G. (1993), 'Evolving images of place in aging and aging in place', Generations, 17(2), 65-70.

Rowles, G. and M. Bernard (2013), 'The meaning and significance of place in old age', in G. Rowles and M. Bernard (eds), Environmental Gerontology: Making Meaningful Places in Old Age, New York: Springer, pp. 3-24.

Rowles, G. and H. Chaudhury (1995), Home and Identity in Later Life: International Perspectives, New York: Springer.

Rubenstein, R. (1990), 'Personal identify and environmental meaning in later life', Journal of Aging Studies, 4(2), 131-47.

Sanford, J. (2012), Universal Design as a Rehabilitation Strategy: Design for the Ages, New York: Springer.

Saville-Smith, K., M. Rehm, B. James and L. Murphy (2016), Downsizing and the Housing StockRealities for Older People, Wellington: Centre for Research Evaluation and Social Assessment [CRESA].

Smith, A. (2009), Ageing in Urban Neighbourhoods: Place Attachment and Social Exclusion, Bristol: Policy Press.

Tanida, N. (1996), 'What happened to elderly people in the great Hanshin earthquake?', British Medical Journal, 313(7065), 1133-5.

United Nations Department of Economic and Social Affairs [UN] (2017), World Population Ageing 2017: Highlights, New York: United Nations.

United Nations Department of Economic and Social Affairs [UN] (2019a), World Population Prospects 2019: Volume 1: Comprehensive Tables, New York: United Nations.

United Nations Department of Economic and Social Affairs [UN] (2019b), World Population Prospects 2019: Data Booklet, New York: United Nations.

United Nations Department of Economic and Social Affairs [UN] (2019c), The Sustainable Development Goals Report, 2019, New York: United Nations.

Van der Pas, S. (2009), 'Living arrangements, ageing in place and well-being among older New Zealanders', in P. Koopman-Boyden and C. Waldegrave (eds), Enhancing Well-being in an Ageing Society: 65-84 Year Old New Zealanders in 2007, Hamilton: The Population Studies Centre, University of Waikato/Wellington: Family Centre Social Policy Research Unit,, pp. 133-52.

Wahl, H.-W. and G. Weisman (2003), 'Environmental gerontology at the beginning of the new millennium: reflections on its historical, empirical, and theoretical development', The Gerontologist, 43(5), 616-27.

Wakabayashi, Y. (2020), 'Mapping the problems of housing vacancies in Japan', in T. Kubo and Y. Yui (eds), The Rise in Vacant Housing in Post-Growth Japan: Housing Market, Urban Policy, and Revitalizing Aging Cities, Singapore: Springer Nature, pp. 23-32.

Webb, J., B. Williams and K. Smith (2011), 'Redefining design and disability: a person-environment fit model', in W. Preiser and K. Smith (eds), Universal Design Handbook, 2nd edition, New York: McGraw-Hill, pp. 43.1-43.8.

Wiles, J., R. Allen and A. Palmer et al. (2009), 'Older people and their social spaces: a study of well-being and attachment to place in Aotearoa New Zealand', Social Science and Medicine, 68(4), 664-71.

Wiles, J., A. Leibing and N. Guberman et al. (2012), 'The meaning of aging in place to older people', The Gerontologist, 52(3), 357-66. 
World Health Organization [WHO] (2007), Global Age-friendly Cities: A Guide, Geneva: WHO.

World Health Organization [WHO] (2015), World Report on Ageing and Health, Geneva: WHO.

World Health Organization [WHO] (2017), Global Strategy and Action Plan on Ageing and Health, Geneva: WHO.

World Health Organization [WHO] (2020a), 'Countries and areas of the WHO Western Pacific Region' [map], accessed 23 April 2020 at https:/www.who.int/westernpacific/about/where-we-work.

World Health Organization [WHO] (2020b), Decade of Healthy Ageing (2020-2030), accessed 23 April 2020 at https:/www.who.int/docs/default-source/decade-of-healthy-ageing/final-decade-proposal/ decade-proposal-final-apr2020-en.pdf?sfvrsn=b4b75ebc 3 .

Wu, Y.-Z., M. Prina and L. Barnes et al. (2015), 'Relocation at older age: results from the cognitive function and ageing study', Journal of Public Health, 37(3), 480-87.

Yu, J. and M. Rosenberg (2017), "No place like home": aging in post-reform Beijing', Health and Place, 46, 192-200. 